Educación Física y Ciencia, vol. 19, n 1, e022, junio 2017. ISSN 2314-2561

Universidad Nacional de La Plata.

Facultad de Humanidades y Ciencias de la Educación.

Departamento de Educación Física

\title{
Boxeo femenino: Sacrificios, puños, sudor y lágrimas
}

\author{
Female boxing: Sacrifices, punches, sweat and tears
}

\author{
Fernando Antonio De La Espriella Arenas *; Mónica Segura Contreras * \\ *Universidad de Córdoba, Colombia | ferdelae@gmail.com; mseguraantsantos@hotmail.com
}

\section{PALABRAS CLAVE}

Historias de vida

Boxeo femenino

Resistencia

Género

Resiliencia

\section{KEYWORDS}

Story of life

Female Boxing

Strength

Gender

Resilient

\section{RESUMEN}

El presente artículo es derivado de una investigación financiada por la Universidad de Córdoba; pretende desde el enfoque cualitativo develar la historia de vida de una excampeona mundial de boxeo femenino en Colombia. A partir de los relatos, que muestran su realidad individual y social, se hace un ejercicio de comprensión e interpretación de sentidos y significados, motivaciones, experiencias y vivencias entramadas en la vida de esta representante del género en el pugilismo nacional. Como resultados podemos encontrar una vida llena de sacrificios y privaciones, una familia resiliente y una mujer que desarrollo estrategias de resistencia para no dejarse devorar por las adversidades. Su vida es digna de ubicarla como referente y ejemplo de las generaciones futuras de deportistas; de ella como mujer tenemos mucho que aprender, por supuesto sobre boxeo, pero también y por encima de todo sobre nosotros mismos.

\section{ABSTRACT}

The following article is a branch of a research sponsored by the University of Cordoba; from the qualitative approach, it aims to reveal the life story of a former world champion in female boxing in Colombia. From the tales, which show her personal and social reality, an exercise of comprehension and interpretation of the senses and meanings, motivations, experiences and walk of life ingrown in the life of this representative of the gender in the national Boxing was done. As a result, we can find a life full of sacrifices and deprivations, a resilient family and a woman who strengthened herself not to be pulled down by the adversities. Her life is worth telling as an example and role model to the upcoming sports generations; a woman who we all have something to learn from, not only about boxing but also about ourselves. 


\section{Introducción}

La ética profesional del sacrificio posibilita a los boxeadores escapar del mundo cotidiano y crear un universo sensual y moral "sui generis" donde un trascendente ser masculino - femenino- puede ser construido. Wacquant (2006)

La historia de vida es considerada como uno de los métodos de investigación más importantes de las Ciencias Sociales y humanas. En ellas se han registrado testimonios orales, a través de los cuales se caracterizan problemas relevantes y se buscan nuevas explicaciones del acontecer humano. Cardín (2013) asegura que las historias de vida son el resultado de la praxis, es decir, del movimiento dialéctico de las experiencias individuales acumuladas con las limitaciones, y las oportunidades proporcionadas por la estructura política y económica. Lo anterior, en atención a que el hombre no es un dato sino un proceso, el cual actúa en forma creativa en su mundo cotidiano.

Para lograr una buena historia de vida, el investigador además de establecer relación dialógica con el informante, debe adentrarse a la realidad social que lo rodea; así ayuda a dar un sentido más profundo a los relatos (De La Espriella, 2013). En este sentido, Taylor y Bogdan (1998) sostienen que la historia de vida, busca capturar información, viendo las cosas desde la perspectiva de las personas, quienes están continuamente interpretándose y definiéndose en diferentes situaciones. Por consiguiente, la historia de vida, como método investigación cualitativa, busca descubrir la relación dialéctica, la negociación cotidiana entre aspiración y posibilidad, entre utopía y realidad, entre creación y aceptación (Ruiz Olabuénaga, 2012); en consecuencia, sus datos provienen de las experiencias de la vida cotidiana, del sentido común, de las representaciones que el sujeto construye para vivir y sobrevivir diariamente.

Bertaux y Bertaux (1993; citados por Bassi, 2014) sostienen que los relatos de vida nos interesan, no es porque sean historias personales - con las que no tenemos nada que hacer - sino porque estas historias -personales- no son sino el pretexto para describir un universo social desconocido. Por tanto, a través de los ojos del narrador, no es a él a quien queremos mirar, sino al mundo; o, con más precisión, a su mundo. El mundo que nos interesa conocer es el que está entramado en la historia de vida de nuestra entrevistada, ese mundo escasamente conocido de las boxeadoras, el cual es poco atractivo y espectacular para los medios de comunicación. Ese mundo que Wacquant (2007) define como: la monótona y obsesiva rutina diaria de ejercicios y la interminable e ingrata preparación física y moral. En definitiva, las historias de vida son un pretexto para investigar -conocer- cómo funciona el mundo de la vida de los sujetos y la sociedad.

\section{Metodología}

Las historias de vida como una modalidad de investigación social cualitativa, comparte las particularidades o características metodológicas de este enfoque investigativo; el recorrido metodológico adoptado en esta investigación fue el sugerido por Galeano (2004) quien sostiene que esta presenta tres momentos articulados entre sí y con relación de simultaneidad: exploración, descripción, análisis.

La exploración, fue un ejercicio de acercamiento e interacción con la entrevistada; en estos encuentros a partir del diálogo y la conversación se logró crear una atmosfera segura, una relación de confianza y aceptación. Llegar a este punto resultó sencillo, ya que la entrevistada mostró desde el comienzo -la reunión individual con la entrevistada, donde se le explicó el propósito del estudio y el alcance de la información que ella compartiera- un gran interés y predisposición para contarnos su historia de vida. Saltalamacchia (1992; citado por De La Espriella, 2013) sostiene que la espontánea productividad de una entrevista sólo es asegurada si, antes de ella, el entrevistador se familiarizó profundamente con el universo fáctico y cultural del entrevistado. En este momento de la relación investigador-entrevistada quedaron explícitos los objetivos 
y contenidos de la investigación, a su vez que se obtuvo el consentimiento informado.

Una vez lo anterior, se concertaron las entrevistas, lugar y duración de las mismas, nos aseguramos que estas se desarrollaran en un ambiente cómodo y seguro para la entrevistada. La entrevista en profundidad fue la técnica elegida, ya que esta por sus características permite ir hilvanando cada aspecto de la historia de vida. Por consiguiente, se elaboró un esquema, que permitió establecer un hilo conductor cronológico: familia, infancia, adolescencia, juventud, adultez. Además de la anterior técnica de recogida de información, se utilizó la observación directa - se observaron sus entrenamientos, la vida en casa, en el barrio - y la revisión de archivos personales e institucionales - álbumes de fotografías personales y familiares -.

Cada entrevista quedó grabada en audio y video. Gracias a su naturaleza de mujer sencilla y espontánea, se desarrolló empatía desde el principio, la cual fue mejorando con el paso de los días, a medida que nos confiaba su vida, la de su familia y la de la comunidad donde creció. De La Espriella (2013) sostiene que durante las entrevistas debe existir una interrelación entre la fuente y el investigador, ello permite que el informante elabore y transmita de forma fluida y espontánea sus recuerdos y vivencias personal y colectiva. Cuando algún aspecto no quedaba claro se registraba en el cuaderno de notas y posteriormente, en algún momento, se le pedía que ampliara esos puntos que eran confusos.

La actitud de los investigadores fue de escucha permanente, estuvimos atentos a cada relato, captando todos los detalles de lo que ocurría. Efectivamente, en ese momento nuestra capacidad de asombro estaba a flor de piel; debemos confesar que la sentíamos frente a nosotros, y hasta hubo momentos en que creímos ser parte de su historia de vida. Todo ello porque nos dejamos llevar por su saber sobre sí misma, saber que iluminaba los ámbitos de su realidad social. Tójar (2006) sostiene que ser un buen oyente significa tener paciencia, ser atento y respetuoso con las personas con las que se trata y con las cosas que éstas nos dicen.

Profesamos absoluto respeto por todo lo escuchado durante la entrevista, solo se intervino en los momentos que por razones de su emotividad se desviaba del tema; para ello se le hacía una pregunta que permitiera recuperar el hilo conductor de la entrevista. Siempre nos mostramos empáticos, atentos y respetuosos, sin ocultar la profunda emoción y sentimientos encontrados que generaba cada delato de su vida; la vida de una mujer excepcional que se hizo boxeadora profesional y ganó un título mundial habiendo pasado por vicisitudes que le acompañaron desde la niñez hasta la edad adulta.

De acuerdo con Muratorio (2005), El rol del entrevistador y la relación personal e intelectual entre los dos interlocutores:

“Ocupa un lugar central en el proceso de construir historias de vida. La auto-conciencia del entrevistador, sus supuestos culturales y su bagaje intelectual, en suma, su autobiografía, seencuentra- con la del narrador. Como en cualquier otra buena conversación, al hacer historia oral, aprender a escuchar, incluyendo una detenida atención a los silencios, supone en buena medida una renuncia al ego. Esto no significa convertirse en un observador neutral sino precisamente lo opuesto; ser un buen oyente siempre requiere simpatía”.

La descripción, es un ejercicio que permite pasar lo expresado en las entrevistas a la escritura. Chárriez (2012) sostiene que la transcripción de los relatos debe darse lo más fidedignamente posible, con toda su riqueza -lenguaje, lapsus, modismos, entre otros-. Por su parte, De La Espriella (2013) afirma que las transcripciones ofrecen un cúmulo de datos que por momentos parecen inconexos y sin sentido; sin embargo, es tarea del investigador ordenarlos y clasificarlos sin desechar nada, sin cambiar una sola palabra, aunque estuviese mal pronunciada. En ese sentido, el estilo y ordenamiento de sus palabras se conservaron y cuidaron por completo. Ruíz Olabuenágana (2012, citado por Chárriez, 2012) sostiene que la construcción de la historia de vida, es decir la confección del texto, no se aborda una vez concluidos los momentos anteriores, sino que se inicia desde los primeros encuentros y acompaña la investigación en todas sus fases. En ese 
sentido, la transcripción es en sí misma un proceso de construcción de información; por consiguiente, el ejercicio de transcribir lo registrado en las grabaciones -relatos- y las notas de campo constituyó todo un reto que provocó desequilibrios cognitivos a los investigadores.

El análisis, es decir, el resultado o construcción de sentidos, comienza con el conocimiento íntimo de los datos -minucioso relato en primera persona-, con la lectura y relectura de las transcripciones. Toda la transcripción - libre de cualquier sesgo - derivada de la información recogida en las entrevistas, observación directa, notas de campo, entre otras, fue leída varias veces, luego se escuchaba y observaban en los videos. De La Espriella (2013) afirma que la revisión minuciosa de las grabaciones de audio y video, y la lectura de los manuscritos permiten ir hilando cronológicamente el texto y ordenando todos los elementos, que facilitan la construcción de sentidos de la historia de vida. Es decir, relatar la vida tal y como nos fue expuesta. A este ejercicio se le denomina interpretación - comprensión; sobre esta relación Gadamer (1993; citado por Peña, 2008) sostiene que la interpretación no es un acto complementario y posterior al de la comprensión, sino que comprender es siempre interpretar; en consecuencia, la interpretación es la forma explícita de la comprensión.

\section{Resultados}

\section{Relatos de una vida y construcción de sentidos.}

Construir una historia a partir de sus recuerdos y vivencias, es un reto al que se mide la entrevistada. Estimular su memoria, poner en funcionamiento y avivar la urdimbre de sus recuerdos jamás desenterrados, del registro de suinconsciente y ser fundados en el diálogo con el otro, le conceden a la protagonista de la historia el carácter de ideóloga de su propia existencia.

De La Espriella (2013)

El relato es parte esencial en la reconstrucción de la historia de vida. Ello significa hacerlo legible sin que se atribuyan al protagonista cosas que no dijo o tergiversado el significado de sus palabras. De acuerdo a lo anterior, Chárriez (2012) sostiene que el investigador que utilice una metodología cualitativa -historia de vida- ha de tener la capacidad para obtener información de forma simultánea, sin optar por la fragmentación y descontextualización de los fenómenos que estudia.

Por su parte, el sentido se entiende como el lugar que ocupan los hechos en la -estructura de relevancias - que organizan la percepción activa del sujeto. Esa estructura de relevancias está fundada, por supuesto, en los valores, saberes y certezas que, según se supone, el entrevistado comparte, en algunos casos, con casi todos sus contemporáneos y, en otros, con sólo algunos de ellos. De igual forma, entra en juego el reconocimiento del otro como única posibilidad para la comprensión - interpretación de lo que dice. El ejercicio de interpretar es conjetural, las conjeturas sobre el sentido y la verdad se hacen sobre el texto, no sobre el sentido del sujeto, aunque el sujeto está puesto en el texto (Peña, 2008).

La protagonista de esta historia de vida es una boxeadora colombiana, que ha irrumpido con tenacidad en un deporte que, a consideración de muchos es solo para hombres. A los 27 años de edad ganó el primer título mundial de boxeo femenino para Colombia en el peso súper ligero del Consejo Mundial de Boxeo -CMB-.

Su relato es fiel a la realidad que vivió, al recuerdo personal de la realidad en que habita, tiene en cuenta aspectos cronológicos, lugares y espacios que hacen parte de su vida pública y privada. Durante esos momentos de interacción develó el placer que le producía darnos esas explicaciones, hacernos comprender, introducirnos en su universo. Al contar su vida viajaba a través de ella, revivió momentos de gran conmoción 
que nos hicieron brotar lágrimas.

Hay que escuchar su llamado y dejarse llevar por su voz tranquila y cadenciosa. Su voz posee una extraña y desgarradora belleza. Con ella teje la vida de toda una familia, una comunidad, una clase obrera y oprimida que lucha a diario en el umbral de la estabilidad socio-económica. En este relato cada palabra y cada gesto cobran sentido. Por consiguiente, al relatar su historia de vida, deja manifiesta la lucha constante que tienen las pugilistas y otras deportistas de su talla en nuestro país, que para alcanzar la gloria deben luchar, sudar y entrenar todos los días, con mucha pasión y esmero. No obstante, solo son tenidas en consideración cuando están consiguiendo títulos o medallas, de lo contrario son discriminadas, marginadas, rechazadas e invisibilizadas; es decir, conminadas al absoluto olvido. Sobre lo anterior Sojo y Cota (2014) sostienen,

"con todo y que la participación de la mujer en el deporte es un hecho, los resultados muestran una invisibilización en el escenario público. Son muy pocas las noticias e imágenes de mujeres deportistas, directivas y entrenadoras; la mayor parte del espacio en las secciones deportivas estudiadas se dedica a los hombres, lo que refleja no solo invisibilización, sino opresión, exclusión y discriminación, como resultado de un sistema patriarcal”.

Igual que durante su niñez, la etapa de la juventud ha estado atravesada también por las dificultades y los sacrificios. Cuando decide marcharse con su esposo para Arjona - Municipio del Departamento de Bolívar, muy cerca a Cartagena-, en busca de oportunidades y mejores opciones en su vida como boxeadora, también experimenta dificultades y carencias. A pesar de contar con el apoyo moral de sus padres y una promesa de conocer a quien sería su entrenador, el desarraigo y el desprendimiento del círculo familiar trajeron consigo vicisitudes propias de quienes se arriesgan a salir de su contexto y enfrentarse a la suerte. Los primeros meses en el municipio de Arjona padecieron desempleo, rechazo y discriminación, hasta el punto de ser desalojados y verse sometidos a dormir en el suelo por tres meses. Situaciones que degradan la condición humana.

Cuando nos fuimos para Arjona, allá pasemos (sic) muchas dificultades también, ya que nosotros no teníamos familia allá. En Arjona no teníamos a nadie, solamente nos íbamos para donde un amigo que nos iba a presentar al profesor José de la Cruz. Nos tocó dormir en el suelo, en el suelo duremos durmiendo tres meses, pues ya que la facilidad para irnos para un lugar no era la adecuada, porque no teníamos el dinero para alquilar una pieza.

Una señora, que se llama Bernabela Teherán, nos ayudó mucho, ella es la mamá de los boxeadores reconocidos Marriaga, unos grandes boxeadores. También ella nos ayudó bastante, nos dijo: no mijitos, no se preocupen, yo les voy a regalar una camita de un puesto que tengo ahí, y se van con esa camita. Y así, fue como la señora nos dio la camita y nos dijo: tienen que comprarle unas tablas y una colchoneta, porque no tenemos más. Nos regaló esa cama de un puesto y nosotros le compremos (sic) la colchoneta y las tablas. Y ahí empecemos (sic) a vivir, de ahí en adelante vivíamos solos, y esa señora nos ayudó mucho.

Se podría señalar que el sacrificio es una de las improntas de los boxeadores. Wacquant (2006) sostiene que, la moral propia de los boxeadores profesionales está encapsulada en una sola palabra -sacrificio-, sacrificio significa al mismo tiempo medio y fin, obligación vital y misión orgullosa, exigencia práctica y obsesión etológica. Lo anteriormente descrito, se evidencia en la protagonista de la historia, quien pone sus aspiraciones de ser boxeadora profesional por encima de todo, ello le permitió resistir las vicisitudes del camino.

En consecuencia, cualquier pugilista profesional - sea mujer u hombre- merecedor de tal nombre, sabe que debe entregarse a su oficio en cuerpo y alma, así, sin importar nada. Ella entendió que su compromiso como boxeadora tenía que ser total y avasallador. Su condición de boxeadora de élite, le hace colocar su oficio por 
encima de cualquier otra cosa, sea familia, hijos, amigos, esposo, trabajo -si tiene- y todas las preocupaciones mundanas a las que estamos expuestos cada día y que se nos imponen socialmente. Sus energías físicas, mentales y emocionales deben cultivarse a conciencia, valorarse y estar encaminadas metódicamente hacia un único y exclusivo objetivo: maximizar la destreza de los puños y conseguir el mayor rendimiento en el cuadrilátero (Wacquant, 2006).

Durante las entrevistas los temas abordados fueron muchos, ella además de relatar su historia de vida, también se atrevió a opinar sobre diversos asuntos. Sus conocimientos son válidos, en tanto contribuyen a comprender la realidad, ya que como partícipe de una realidad social aporta conocimientos que pueden ser diferentes a los de la academia, pero que indudablemente tienen validez. Con ella dialogamos sobre política, cultura, boxeo, la muerte, el amor y el matrimonio, sobre cómo quiere ser recordada, y ofreció sus consejos a la juventud.

Se declara apolítica, no le gusta para nada la política. Una vez en época de campaña electoral, se vio su fotografía en buses de servicio público urbano en apoyo a un candidato a la cámara de representantes. Esto, según ella, generó mucha polémica y discusión con los apoderados que tenía para ese momento, quienes sin permiso colocaron su fotografía. De eso nunca fue consultada ni enterada, no sabía nada al respecto; cuando logró verla llamo a su representante y le preguntó por qué habían colocado esa foto sin su permiso, su apoderado le respondió que él como su representante podía hacerlo, además ese político iba a respaldar una velada boxística. Ante esa respuesta ella le manifestó que no quería que esa foto estuviera ahí, porque no estaba con ningún político. Esto generó un conflicto y desde ahí se vinieron muchos desacuerdos con esa empresa boxística, hasta el punto de romper contrato con ellos.

Económicamente el boxeo me ha ayudado bastante, gracias a Dios, como le dije, que cuando nosotros estábamos en Arjona no teníamos nada, y a medida que lo económico que nos ha dado el boxeo, siempre lo invertimos en lo que necesitamos en la casa. Gracias a Dios todo lo hemos obtenido con sacrificio y día a día hemos ido amueblando(sic) la casa.

El boxeo no es que me dé estabilidad económica, gracias a Dios mi esposo trabaja y el boxeo es como una ayuda para lo que necesitamos, porque si no peliamos(sic) no ganamos dinero, eso es lo que tiene el boxeo profesional, que si uno no pelea no gana, entonces no es una estabilidad económica.

La pelea en la que más he ganado es la que hice en África, porque cuando pelié título mundial con Cris Namús me pagaron \$1.500.000, y me los pagaron en cuatro partidas, que por eso era también la inconformidad con los apoderados. Muchas personas creían que me gané tantos millones, hubo una especulación de que me gané \$500.000.000, tanto así la especulación que se me intentaron meter en la casa donde vivía alquilada, me abrieron la puerta del patio y Bravo tuvo que hacer un disparo, porque habían abierto la puerta y todo eso. Después especularon de que eran \$ 200.000.000, y yo les dije, yo hasta con 100.000 .000 me retiro, monto un negocio y no tengo que peliar más, ¡imagínese usted!...

Yo tuve que publicar eso, y decir la verdad. También tuve muchos problemas con los representantes y tuve que decir la verdad, porque ellos no querían que dijera la verdad, entonces ellos quedaban bien y quedaba mal yo. Entonces tuve que decir la verdad y por eso se vino también la diferencia entre ellos y yo.

Respecto de la relación boxeador - empresario o manager, Wacquant (2007) sostiene: 
"Los boxeadores son jóvenes ásperos, casi analfabetos que, crecieron en hogares desintegrados y con privaciones, que se las arreglaron por sí mismos para salir de una cuneta y llegar a la fama y la fortuna, cambiando su ira hacia el mundo y las ansias de violencia sadomasoquista en millones de dólares, salvo por aquellos que, cruel y despiadadamente han sido explotados por los managers y promotores, y acabaron en la miseria con los huesos y el corazón rotos”.

De hecho, ella terminó con el corazón roto por sus managers y promotores, quienes la explotaron y utilizaron. La causa del rompimiento del contrato no solo fue la valla publicitaria, sino una suma de situaciones como la que ella describe cuando le pagaron la pelea de título mundial. En la práctica del - noble arte -, sean hombres o mujeres, el cuerpo del púgil es al mismo tiempo su herramienta de trabajo: arma de ataque, escudo de defensa y protección al igual que blanco de los golpes del adversario (Wacquant, 2006). En este deporte no hay diferencia alguna en cuanto al género, ambos en la práctica exponen y arriesgan la vida. Moreno (2011), sostiene que las boxeadoras, además de experimentar en carne propia las más exacerbadas contradicciones de la desigualdad de género, además de someterse a un ejercicio disciplinario extremo, sufren el deterioro consiguiente de una práctica deportiva extremadamente peligrosa.

En consecuencia, otorgar menor relevancia a las mujeres boxeadoras excluirlas e invisibilizarlas es una práctica eminentemente inequitativa, una forma de violencia simbólica de la dominación masculina en el boxeo; sobre todo en tiempos donde la figura de la mujer cobra relevancia y atención a nivel mundial. La exclusividad y hegemonía de los hombres en el deporte, y particularmente en el boxeo, ya es asunto del pasado. Mantener en el anonimato a estas gladiadoras aporta poco a la construcción de sociedades justas e incluyentes.

Nuestra protagonista, quiere ser recordada, en lo deportivo, por todo lo que ha hecho en el boxeo; por las representaciones en este deporte a nivel mundial, dejando a Colombia, Córdoba y Montería en alto. En su vida personal, como una persona sencilla, humilde y con muchas ganas de triunfar. Afirma: "porque yo he triunfado bastante, grandes triunfos me ha dado Dios; tanto en la vida espiritual como de vida normal en este mundo".

Sobre su retiro del boxeo, poco ha pensado, pero cuando se retire se dedicará a la familia, "tengo un solo hijo, de pronto puedo tener uno o dos más, una familia grande, porque cuando el hijo va creciendo se le va con su familia y va quedando uno solo y entonces una familia grande no me deja quedar solita”.

Sobre la realidad del boxeo femenino en Córdoba y Colombia, señala que los deportistas no tienen el apoyo que necesitan. Afirma que los deportistas para salir adelante y llegar donde quieren, tienen que hacerlo con las uñas, pasar muchos sacrificios y tener mucha dedicación y amor por lo que les gusta y desean. Esta es la realidad del deporte en Córdoba, donde el único coliseo cubierto que se tenía fue demolido durante la realización de los juegos nacionales del 2012 con la promesa de remodelarlo, y aún no se concluye. A la fecha este escenario deportivo donde se practicaban diferentes disciplinas deportivas, entre ellas el boxeo, aún está cerrado, generando inconmensurables perjuicios a los deportistas, el impacto negativo al deporte aún no se ha dimensionado. Esta realidad abrumadora y nefasta le impide a ella asegurar que, en el futuro, cuando se retire, pueda dedicarse a ser entrenadora de boxeo femenino.

Como boxeadora recomienda la práctica del boxeo en las mujeres, entre otras razones señala:

Esto es muy duro, pero yo pienso que sí, así lo hagan para defenderse de los maridos. Porque hay muchos que quieren estarle pegando a las mujeres y no estoy de acuerdo con eso. Las mujeres no nacimos para que nos golpearan, sino para que nos quisieran, pero hay muchos hombres que son mano larga y van es a pegarle a las mujeres y no estoy de acuerdo con eso. 
Se opone rotundamente a la violencia contra la mujer por parte de los hombres. Además, recomienda que las mujeres practiquen deporte, aunque no sea boxeo, porque el deporte proporciona una vida sana. Consustancialmente, su historia de vida es una muestra de capacidad para soportar crisis y adversidades en forma positiva; esa inconmensurable capacidad de resistencia y fortaleza le permitieron en su vida sortear situaciones complejas, como las vividas durante el nacimiento de su primer hijo.

En el momento del parto ya estábamos acá en Montería, en el barrio el Minuto de Dios. Yo me quedaba ahí con mi hermano, me acompañaba en las noches. Mi mamá y mi hermana pasaban en el día ahí conmigo, pero en la noche se iban y quedaba mi hermano, que venía a dormir, acompañarme ahí.

El seis de agosto del 2007 Bravo llegó en la noche y se fue en la madrugada. Ya yo en la noche estaba con bastantes dolores, le decía que tenía era dolor de barriga, porque no sabía (risas...). Le decía: me duele la barriga, no sé que tengo, tengo como dolor de barriga. Y me acosté y él me sobaba la barriga y me decía: "será mijita”; pero era un dolor que no era ni duro, era como ahí cansón (risas...). Entonces, él me dijo: me toca irme en la madrugada, mijita. Yo dije: bueno mijo, sí. Yo me quedo con el pequeño que es mi hermano, bueno (risas...)

Entonces eso fue el seis en la en la noche, y en la madrugada él se fue a las cinco de la mañana y yo quedé con el dolor. Cuando ya eran las seis de la mañana yo no aguantaba el dolor, porque entre más tiempo más me dolía, y yo no sabía y como era primera vez. Yo mandé a buscar una prima mía que ya había alumbrado y le dije de que(sic) yo estaba apurada con bastante dolor, y entonces ella me dijo que si había rompido(sic) fuente, y yo le dije: pero eso qué es, si yo no sé qué es eso. Entonces ella me dijo: no, cuando rompen fuente es que vas al baño y tienes como ganas de ensuciar y te baja una agua como con sangre. Y yo le dije: no, yo todavía no; dice: entonces todavía no, eso es que tienes dolor apenas.

Pues bueno, ahí ella se fue y me dejó sola, quedé yo solita ahí porque el hermano mío salió hacer un mandado, y después como a las siete de la mañana me comenzaron dolores más fuertes y ahí si empecé a romper fuente como ella me dijo. Y yo asustada porque estaba solita, esperé que pasara un pelaito por ahí y lo mandé que la fuera a buscar. Lo llamé y lo mandé que la fuera a buscar y llamé a Bravo, y le dije de que estaba apurada con dolor, con bastante dolor, que me iba a ir para el Camu. Y él me dijo que lo estuviera llamando, para que le avisara. Después la prima mía regresó nuevamente cuando la mandé a buscar con el pelaito, me dijo vámonos para el Camu, porque ya estás casi que alumbras, vámonos en un carro. Yo dije: ¡no! vámonos a pie, porque estábamos cerquita.

Resistirse frente al dolor, desarrollar la capacidad de superar las dificultades, proteger la propia integridad bajo presión apoyándose en sus convicciones, es un comportamiento vital positivo que le permite salir avante frente a circunstancias difíciles. Ella se mantiene incólume, su estructura es fuerte independientemente de las presiones del medio o los choques de la vida.

\section{Consideraciones finales}

Este ejercicio investigativo coincide con lo señalado por Quitián (2010) quien sostiene que explorar las connotaciones socioculturales, de una práctica corporal intensa como el boxeo, resulta ser una aventura académica de dimensiones insospechadas, particulares y universales. Efectivamente, esta aventura cobra relevancia debido a que los estudios de género en el deporte son pocos, más específicamente en el boxeo. Las mujeres en el boxeo en Colombia son una población minoritaria, excluida e invisible; a quienes se les otorgan apoyos y estímulos económicos de manera diferencial, quizás por razones de género. De ahí que sus 
triunfos en este noble arte sean exiguamente reconocidos, tal vez porque la bolsa económica es ostensiblemente minoritaria en comparación con la de los hombres.

Lo anterior tiene asiento en el hecho que el deporte en sus inicios se constituyó a partir de un paradigma meramente masculino que ubicaba a las mujeres en una condición de total exclusión y de absoluta inferioridad. Sobre lo anterior, Rodríguez, Martínez y Mateos (2004) sostienen que a la mujer no le ha sido fácil asumir su corporeidad desde la libertad personal, debido a la consideración implícita que el cuerpo de la mujer no es un cuerpo para ella sino un cuerpo para los otros, bien sea, como madre y receptora de los hijos o cuerpo como conquista y posesión del varón para quien debe estar bella y dispuesta. La imagen de mujer es sinónimo de sumisión, orden y pasividad; equívoca posición cargada de misoginia.

La protagonista de esta historia de vida es una deportista profesional, que le dio a Colombia su primer título mundial de boxeo femenino. Su relato construido en primera persona, refleja una realidad y condiciones de vida que es similar a la de muchas mujeres boxeadoras colombianas y latinoamericanas, quienes en este deporte han irrumpido sin mediar consecuencia alguna y que con sus puños, sudor y lágrimas han salido adelante, derribando toda clase de estereotipos socialmente establecidos. Su historia tiene un hilo conductor que es la resistencia, la capacidad y determinación para salir adelante

La vida de la boxeadora protagonista de esta historia, está llena vivencias y experiencias que merecen ser tomadas como referente social; como ella misma lo afirma: quiero ser un ejemplo para muchas niñas colombianas que están incursionando en este bello deporte, demostrarles que sí se pueden lograr los sueños y que vale la pena luchar para conseguirlos. Es evidente que en Colombia a las boxeadoras profesionales no se les ofrecen muchas posibilidades de crecimiento económico; sin embargo, para ella esto es poco representativo, ante la oportunidad de ser un referente - de trascender- en la sociedad, especialmente ante los y las jóvenes deportistas.

En Colombia y Latinoamérica no es muy común la emergencia de pugilistas del género femenino, sobre todo que desarrollen altos logros deportivos; llegar al nivel de boxeadora profesional, de élite, requiere inconmensurables sacrificios y sufrimientos; estos mismos fueron los que tuvo que pasar la protagonista de esta historia de vida.

La exclusividad y hegemonía de los hombres en el deporte, y particularmente en el boxeo, ya es asunto del pasado. Hoy la mujer cobra un lugar representativo en el deporte nacional e internacional, muestra de ello son los resultados de la medallería olímpica en los juegos de Rio 2016. Seguir apostándole al estereotipo fundado en la supuesta masculinidad del deporte, es moral y socialmente inaceptable. El modelo sexista que ha imperado por tiempos, está llegando a su fin, hoy las mujeres están al nivel de los hombres en el rendimiento deportivo. Corresponde a la academia, la sociedad y los medios de comunicación reconocer tales avances y desarrollos; en consecuencia, mantener en el anonimato a estas gladiadoras aporta poco a la construcción de sociedades justas e incluyentes.

\section{Referencias}

Cardín, E. (2013). La historia de una vida en situación de frontera: migración, superación y trabajo en el “circuito sacoleiro”. Revista de Estudios Sociales. 48:100-109. http://dx.doi.org/10.7440/res48.2014.08

Chárriez, M. (2012). Historias de vida: Una metodología de investigación cualitativa. Revista Griot. 5(1) p, 50-67.

De la Espriella, F. (2013). Historia de vida de Lely Luz Flórez Meza: boxeadora colombiana ex-campeona mundial de la categoría wélter junior del Consejo Mundial de Boxeo (CMB). Educación Física y Deporte. 32(1) p, 1301-1314. 
Galeano M.E. \& Vélez, O. L. (2000). Investigación cualitativa: estados del arte. Informe de investigación. Medellín: Facultad de Ciencias Sociales y Humanas, Universidad de Antioquia.

Galeano M.E. (2004). Diseño de proyectos en la investigación cualitativa. Medellín: Fondo Editorial Universidad Eafit.

Moreno Esparza, H. M. (2011). Orden discursivo y tecnologías de género en el boxeo. México: Instituto Nacional de las Mujeres, INMUJERES. ISBN (volumen 3): 978-607-7825-24-1

Muratorio, B. (2005). Historia de vida de una mujer amazónica: intersección de autobiografía, etnografía e historia. Iconos. Revista de Ciencias Sociales. Num. 21, Quito, mayo 2005, pp. 129-143. Facultad Latinoamericana de Ciencias Sociales-Sede Académica de Ecuador. ISSN: 1390-1249

Peña, M. (2008). Pensar la interpretación: la construcción del sentido en Ciencias Sociales. LiminaR. Estudios Sociales y Humanísticos [en linea], VI (Julio-Diciembre): [Fecha de consulta: 27 de agosto de 2016] Disponible en: <http://www.redalyc.org/articulo.oa?id=74511194012>ISSN 1665-8027

Quitián, D. (2010) Una investigación sobre el tinglado: el deporte como asunto académico y el boxeo como tema antropológico. Revista Lúdica Pedagógica (15) 62-77.

Rodríguez, D., Martínez, M. y Mateos, C. (2004). Identidad y estereotipos de la mujer en el deporte. Una aproximación a la evolución histórica. Recuperado de http://reined.webs.uvigo.es/ojs/index.php/reined/article/view/16

Ruíz Olabuénaga, J. I. (2012). Historias de vida. En Metodología de la Investigación Cualitativa. Bilbao: Universidad de Deusto.

Saltalamacchia, H. (1992). La historia de vida: reflexiones a partir de una experiencia de investigación. Puerto Rico: Ediciones Cijup.

Sojo, B., Coto, E. (2014). ¿Visibilización o invisibilización de la mujer en el deporte costarricense? Revista Lúdica Pedagógica, (20), 47-58

Tójar, J. (2006). Investigación cualitativa: Comprender y actuar. Madrid: Editorial La Muralla, S. A.

Wacquant, L. (2006). Entre las cuerdas: cuadernos de un aprendiz de boxeador. Buenos Aires, Siglo XXI Editores.

Wacquant, L. (2006) Los tres cuerpos del boxeador profesional. Educación Física y Ciencia,8. Disponible en: http://www.fuentesmemoria.fahce.unlp.edu.ar/art revistas/pr.133/pr.133.pdf.

Wacquant, L. (2007). La lógica social del boxeo en el Chicago negro. Hacia una sociología del boxeo [En línea]. Educación Física y $\quad$ Ciencia, $9 . \quad$ Disponible en: http://www.fuentesmemoria.fahce.unlp.edu.ar/art revistas/pr.3303/pr.3303.pdf. Consultada 28/02/2015 